\title{
Survival after intervention in patients with low gradient severe aortic stenosis and preserved left ventricular function
}

\author{
Avishay Grupper, MD, Roy Beigel, MD, Elad Maor, MD, PhD, Rafael Kuperstein, MD, Ilan Hai, MD, \\ Olga Perelshtein, MD, Ilan Goldenberg, MD, Micha Feinberg, MD, and Sagit Ben Zekry, MD
}

Objective: The outcome of aortic valve replacement for patients with low gradient severe aortic stenosis and preserved ejection fraction has been debated. The aim of the present study was to evaluate the effect of aortic valve intervention on survival in that group.

Methods: A cohort of 416 consecutive patients with low gradient severe aortic stenosis (aortic valve area, $\leq 1 \mathrm{~cm}^{2}$; mean pressure gradient, $\left.<40 \mathrm{~mm} \mathrm{Hg}\right)$ and preserved ejection fraction $(\geq 50 \%)$ were identified from the Sheba Medical Center echocardiography database. Clinical data, aortic valve intervention, and death were recorded.

Results: During an average follow-up of 28 months, of 416 study patients (mean age, $76 \pm 14$ years, $42 \%$ men), $97(23 \%)$ underwent aortic valve intervention and 140 (32\%) died. Mantel-Byar analysis showed that the cumulative probability of survival was significantly greater after aortic valve intervention. Multivariate analysis revealed a $49 \%$ reduction in the risk of death after surgery $(P<.05)$. The survival benefit of aortic valve intervention was comparable with adjustment to older age, aortic valve area $\leq 0.8 \mathrm{~cm}^{2}$, and a low $\left(\leq 35 \mathrm{~cm}^{2} / \mathrm{m}^{2}\right)$ or normal $\left(>35 \mathrm{~cm}^{2} / \mathrm{m}^{2}\right)$ stroke volume index.

Conclusions: Our findings suggest that aortic valve intervention is associated with improved survival among patients with low gradient severe aortic stenosis and preserved left ventricular function. The presence of either a low or normal stroke volume index did not affect the mortality benefit. (J Thorac Cardiovasc Surg 2014;148:2823-8)

See related commentary on pages $2828-9$.

Severe aortic stenosis (AS) is a common valvular disease defined as a calculated aortic valve area (AVA) $\leq 1 \mathrm{~cm}^{2}$ and a mean pressure gradient of $\geq 40 \mathrm{~mm} \mathrm{Hg} .{ }^{1,2}$ However, $\leq 30 \%$ of patients with AS and a preserved $(\geq 50 \%)$ ejection fraction $(\mathrm{EF})$ might have the inconsistent results of a reduced AVA $\left(\leq 1.0 \mathrm{~cm}^{2}\right)$ and a lower than expected transvalvular gradient $(<40 \mathrm{~mm} \mathrm{Hg}))^{3-5}$ Previous studies have differentiated these patient populations into those with either a low transvalvular flow (define as a stroke volume index [SVI] of $\leq 35 \mathrm{~mL} / \mathrm{m}^{2}$ ) or normal flow (NF). Accordingly, 4 groups of patients with severe AS and preserved EF were described: patients with NF and a high gradient $(\mathrm{NF} / \mathrm{HG})$, patients with $\mathrm{NF}$ and a low gradient

\footnotetext{
From the Noninvasive Cardiology Unit, Leviev Heart Center, Sheba Medical Center, Tel HaShomer, Israel, and Tel Aviv University Sackler School of Medicine, Tel Aviv, Israel.

Disclosures: Authors have nothing to disclose with regard to commercial support. Drs A.G., R.B., and E.M. contributed equally to the present study.

Received for publication Dec 12, 2013; revisions received March 15, 2014; accepted for publication March 21, 2014; available ahead of print April 27, 2014.

Address for reprints: Sagit Ben Zekry, MD, Noninvasive Cardiology Unit, Leviev

Heart Center, Sheba Medical Center, Tel HaShomer 52621, Israel (E-mail: sagit. benzekry@sheba.health.gov.il).

$0022-5223 / \$ 36.00$

Copyright (C) 2014 by The American Association for Thoracic Surgery

http://dx.doi.org/10.1016/j.jtcvs.2014.03.039
}

(NF/LG), patients with low flow and a $\mathrm{HG}(\mathrm{LF} / \mathrm{HG})$, and patients with LF and a LG (LF/LG). ${ }^{6}$ Agreement has been reached on the survival benefit of aortic valve replacement (AVR) for symptomatic patients with HG (LF or HF) severe AS. Nevertheless, data have been conflicting regarding the effect of aortic intervention for patients with LG severe AS and preserved EF. ${ }^{3,-13}$ Studies have mostly shown that patients with $\mathrm{LF} / \mathrm{LG}$ severe AS and preserved EF will fare better when referred for AVR. ${ }^{3,6-8,10-12}$ However, the results from 1 study suggested that patients with LG/LF severe AS and a normal EF will have outcomes similar to those of patients with moderate AS and that AVR had no significant prognostic effect among these patients. ${ }^{9}$ The aim of the present study was to evaluate the effect of aortic valve intervention (either surgical or transcatheter aortic valve placement) on survival among patients with $L G$ severe $\mathrm{AS}$ and a preserved $\mathrm{EF}$, and whether this was influenced by the presence of either a normal or decreased SVI (NF/LF).

\section{METHODS \\ Patient Population}

Echocardiographic and Doppler studies of patients with severe AS and preserved LVEF were retrospectively reviewed from the Sheba Medical Center echocardiography database from 2004 to 2012. The inclusion criteria were AVA $\leq 1 \mathrm{~cm}^{2}$, mean aortic valve pressure gradient $<40 \mathrm{~mm} \mathrm{Hg}$, and $\mathrm{EF} \geq 50 \%$ (ie, patients with LG severe AS with NF or LF). The exclusion criterion was any other significant valvular disease, defined as any moderate or moderate to severe valvular disease. The institutional review board approved the present study. 


$$
\begin{aligned}
& \text { Abbreviations and Acronyms } \\
& \begin{aligned}
\text { AS } & =\text { aortic stenosis } \\
\text { AVA } & =\text { aortic valve area } \\
\text { AVR } & =\text { aortic valve replacement } \\
\text { BSA } & =\text { body surface area } \\
\text { CI } & =\text { confidence interval } \\
\text { EF } & =\text { ejection fraction } \\
\text { HG } & =\text { high gradient } \\
\text { HR } & =\text { hazard ratio } \\
\text { LF } & =\text { low flow } \\
\text { LG } & =\text { low gradient } \\
\text { LV } & =\text { left ventricular } \\
\text { LVOT } & =\text { left ventricular outflow tract } \\
\text { NF } & =\text { normal flow } \\
\text { SVI } & =\text { stroke volume index }
\end{aligned}
\end{aligned}
$$

\section{Standard Echocardiographic and Doppler Measurements}

Two-dimensional transthoracic echocardiographic and Doppler studies were obtained with clinical ultrasound machines equipped with $3.5-\mathrm{MHz}$ transducers using standard views. The studies were digitally stored (McKesson's Horizon Cardiology Medical Software, Tel Aviv, Israel). The parasternal long-axis view was used to measure the aortic annulus diameter in early systole. Pulsed Doppler in the left ventricular (LV) outflow tract (LVOT) from the apical window allowed us to evaluate the flow. A continuous wave Doppler recording of the flow through the aortic valve was performed from the apical, right parasternal, suprasternal, and subcostal windows to minimize the effect of Doppler angulation with flow. The LV stroke volume was derived using the time velocity interval of the LVOT, assuming a circular geometry of the LVOT. The indexed stroke volume was calculated as the stroke volume divided by the body surface area (BSA). Multiplying the heart rate by the stroke volume allowed us to calculate the cardiac output; the cardiac output indexed to the BSA was also calculated. The AVA was derived from the continuity equation. The indexed AVA to BSA was calculated as the AVA divided by the BSA. Using the continuous wave jet recording, the peak and mean velocity were measured. The peak velocity was derived from the Bernoulli equation, and the mean gradient represents the integral of the maximal velocities acquired throughout all of systole. The LVEF was estimated by the reader.

\section{Clinical Data}

The clinical data were obtained from the Sheba Medical Center computerized patient records. The data included age, gender, BSA, body mass index, a history of smoking, hypertension, hyperlipidemia, diabetes mellitus, renal failure, coronary heart disease, and cerebrovascular disease. Complete clinical data were available for $87 \%$ of the study population. Intervention was defined as either surgical or transcatheter AVR. The decision regarding the choice of aortic valve intervention was made by the treating cardiologist. The decision of transcatheter aortic valve intervention was made by a heart team for patients with prohibitive risk. Mortality was evaluated using the Israeli Ministry of Interior National Registry and was confirmed in all patients; the cause of death was not available.

\section{Statistical Analysis}

The study population was divided into 2 groups (intervention vs medical treatment). The Student $t$ test was used to compare continuous variables, and Fischer's exact test was used to compare dichotomous variables between the 2 groups. The benefit of aortic intervention on the estimated survival was compared, as previously described by Mantel and Byar. ${ }^{14}$ In brief, all subjects began treatment in the conservative treatment group. The subjects who underwent aortic valve intervention were entered into the intervention group on the day of surgery and remained in the intervention group until death or censoring. The patients in the conservative treatment group remained in the no intervention group during the follow-up period. Univariate and multivariate Cox proportional hazards models were used to calculate the hazard ratio (HR) for the time-dependent surgical intervention for survival. The multivariate model included adjustment for age, gender, ischemic heart disease, body mass index, AVA $\left(\leq 0.8 \mathrm{~cm}^{2}\right)$, and aortic valve intervention as a time-dependent covariate. In addition, a propensity score model for the decision to perform aortic valve intervention was calculated for all subjects with available clinical data. The model included age gender, body mass index, mean aortic valve gradient, peak aortic valve velocity, AVA, LVEF, ischemic heart disease, and diabetes mellitus. The propensity score was then entered into the Cox regression analysis of long-term survival. Statistical significance was accepted for a 2 -sided $P<.05$. The statistical analyses were performed using IBM SPSS, version 20.0 (IBM, Armonk, NY).

\section{RESULTS}

A total of 416 patients were identified (age, $76 \pm 14$ years; $42 \%$ men; Table 1) with LG severe AS and a preserved EF. The study population was divided into those with (91 surgical AVR, 6 transcatheter aortic valve placement) and without aortic valve intervention. The baseline characteristics of the study population are listed in Table 1; the groups were similar, although the patients referred for aortic valve intervention were significantly younger. The patients' echocardiographic parameters are listed in Table 2. LV function was comparable in both groups. In contrast to the medical group, the intervention group was characterized by a larger LV mass, higher gradients, a higher SVI, and a reduced AVA. Of the 416 patients, 303 had NF and 113 had LF. The LF group had a significantly greater BSA $(1.9 \pm 0.2$ vs $1.8 \pm$ $\left.0.2 \mathrm{~m}^{2}\right)$ and body mass index ( $30 \pm 6$ vs $\left.27 \pm 6 \mathrm{~kg} / \mathrm{m}^{2}\right)$. The LV dimensions and mass were comparable between the 2 groups, and the Doppler parameters revealed a significantly lower peak velocity $(3.4 \pm 0.4 \mathrm{vs} 3.67 \mathrm{~m} / \mathrm{s})$, mean gradient $(27 \pm 7.5$ vs $31.4 \pm 0.6 \mathrm{~mm} \mathrm{Hg})$, stroke volume (57.6 vs $74.1 \mathrm{~mL})$, cardiac index $\left(2.5 \mathrm{vs} 3.1 \mathrm{~L} / \mathrm{min} / \mathrm{m}^{2}\right)$, and EF $(58.8 \%$ vs $60.1 \%)$ in the LF group.

\section{Aortic Intervention and Survival}

During the follow-up period $(28 \pm 25$ months $)$, 143 patients $(32 \%)$ died. The 30-day mortality rate for the patients who underwent surgical or transcatheter aortic intervention was $16 \%(\mathrm{n}=15)$. The average follow-up period until aortic valve intervention was $11.3 \pm 16.4$ months. Mantel-Byar curve analysis revealed a significantly greater cumulative probability of survival after AVR $(P=.001$; Figure 1). Consistently, multivariate analysis showed that time-dependent AVR was associated with a $49 \%$ reduction in the risk of death $(P<.05$; Table 3$)$. A similar reduction in the risk of death was obtained when a propensity score for the decision to perform aortic 
TABLE 1. Baseline characteristics

\begin{tabular}{lccc}
\hline & & \multicolumn{2}{c}{ Aortic valve intervention } \\
\cline { 3 - 4 } \multicolumn{1}{c}{ Parameter } & All $(\mathbf{n}=\mathbf{4 1 6})$ & No $(\mathbf{n}=\mathbf{3 1 9})$ & Yes $(\mathbf{n}=\mathbf{9 7})$ \\
\hline Male gender & $174(42)$ & $126(40)$ & $48(50)$ \\
Age $(\mathrm{y})$ & $76 \pm 14$ & $78.6 \pm 10.5^{*}$ & $73.3 \pm 11$ \\
Age $>80 \mathrm{y}$ & $199(48)$ & $173(54)^{*}$ & $26(27)$ \\
Body mass index $\left(\mathrm{kg} / \mathrm{m}^{2}\right)$ & $28.1 \pm 5.2$ & $28 \pm 5.5$ & $28.1 \pm 4.3$ \\
Body surface area $\left(\mathrm{m}^{2}\right)$ & $1.8 \pm 0.2$ & $1.8 \pm 0.2$ & $1.8 \pm 0.2$ \\
Diabetes mellitus & $132(32)$ & $92(35)$ & $40(41)$ \\
Hypertension & $246(59)$ & $183(69)$ & $63(65)$ \\
Dyslipidemia & $178(43)$ & $132(50)$ & $46(47)$ \\
Active smoker & $22(5)$ & $17(6)$ & $5(5)$ \\
Chronic renal failure & $83(20)$ & $67(25)$ & $16(17)$ \\
Ischemic heart disease & $166(40)$ & $122(46)$ & $44(45)$ \\
Cerebrovascular disease & $66(16)$ & $52(20)$ & $14(14)$ \\
\hline
\end{tabular}

Data presented as $\mathrm{n}(\%)$ or mean \pm standard deviation. $* P<.05$ versus aortic valve intervention.

valve intervention was entered as a covariate in to the Cox regression model (HR, 0.54; 95\% confidence interval [CI], 0.29-0.98; $P<.05)$. In addition, comparable results were noted after the exclusion of 6 patients who had undergone transcatheter AVR (HR, 0.34; 95\% CI, 0.17-0.68; $P<.05)$.

Older age $(>80$ years $)$ and a reduced AVA $\left(\leq 0.8 \mathrm{~cm}^{2}\right)$ were associated with a significant increase in the risk of death $(\mathrm{HR}, 4.7$ and 1.7 respectively; $P<.05)$. The effect of intervention on the cumulative survival rate was further analyzed in 3 different subgroups (Figure 2). Aortic valve intervention had a similar positive effect on survival in the $\mathrm{LF}$ and $\mathrm{NF}$ ( $\mathrm{SVI} \leq 35 \mathrm{vs}>35 \mathrm{~mL} / \mathrm{m}^{2}$ ) subgroup, older age subgroup, and in the subgroup with the cutoff AVA value decreased from 1 to $0.8 \mathrm{~cm}^{2}$ (Figure 2). Univariate Cox regression subanalysis of patients who underwent aortic valve intervention showed that the indexed AVA did not affect survival (HR, 0.977; 95\% CI, 0.896-1.065; $P=.599)$. Similar results were obtained in a multivariate Cox regression model that included an adjustment for age and gender (HR, 0.969; 95\% CI, 0.893-1.051; $P=.448)$.

\section{DISCUSSION}

The results from the present study have demonstrated that aortic valve intervention improves the prognosis of patients with LG severe AS and a preserved EF. The mortality benefit was seen in those with either a normal or decreased SVI, older patients, and those with a reduced AVA $\left(\leq 0.8 \mathrm{~cm}^{2}\right)$. A consistent positive effect of aortic valve intervention was noted when a propensity score was entered as a covariate in the Cox regression model.

\section{Diagnosis of LG Severe AS With Preserved EF}

The evaluation of patients with inconsistency in the aortic valve gradient and calculated AVA is challenging. This is emphasized in the presence of normal LV function. Awareness of the echocardiographic pitfalls is important,
TABLE 2. Echocardiographic characteristics

\begin{tabular}{|c|c|c|c|}
\hline \multirow[b]{2}{*}{ Parameter } & \multirow[b]{2}{*}{$\begin{array}{c}\text { All } \\
(n=416)\end{array}$} & \multicolumn{2}{|c|}{ Aortic valve intervention } \\
\hline & & $\begin{array}{c}\text { No } \\
(\mathrm{n}=\mathbf{3 1 9})\end{array}$ & $\begin{array}{c}\text { Yes } \\
(\mathbf{n}=\mathbf{9 7})\end{array}$ \\
\hline $\mathrm{EF}(\%)$ & $60 \pm 5$ & $60 \pm 5$ & $59 \pm 5$ \\
\hline LV diastolic dimension $(\mathrm{cm})$ & $4.6 \pm 0.5$ & $4.5 \pm 0.5^{*}$ & $4.7 \pm 0.5$ \\
\hline LV systolic dimension $(\mathrm{cm})$ & $2.7 \pm 0.5$ & $2.7 \pm 0.5^{*}$ & $2.8 \pm 0.6$ \\
\hline Septum width (cm) & $1.2 \pm 0.2$ & $1.2 \pm 0.2$ & $1.2 \pm 0.2$ \\
\hline Posterior wall thickness $(\mathrm{cm})$ & $1.1 \pm 0.2$ & $1.1 \pm 0.2$ & $1.1 \pm 0.2$ \\
\hline LV mass (g) & $193 \pm 47.6$ & $190 \pm 46^{*}$ & $202.9 \pm 51.5$ \\
\hline LV mass index $\left(\mathrm{g} / \mathrm{m}^{2}\right)$ & $107.7 \pm 24.4$ & $106.3 \pm 23.8$ & $112.3 \pm 26.1$ \\
\hline LVOT diameter (cm) & $2 \pm 0.1$ & $2 \pm 0.1$ & $2 \pm 0.1$ \\
\hline Stroke volume (mL) & $69.7 \pm 12.1$ & $68.8 \pm 12.3$ & $72.3 \pm 11.2$ \\
\hline Stroke volume index $\left(\mathrm{mL} / \mathrm{m}^{2}\right)$ & $39.1 \pm 7$ & $38.7 \pm 7.2^{*}$ & $40.3 \pm 6.2$ \\
\hline Cardiac index $\left(\mathrm{L} / \mathrm{min} / \mathrm{m}^{2}\right)$ & $2.7 \pm 0.5$ & $2.7 \pm 0.5$ & $2.7 \pm 0.5$ \\
\hline $\operatorname{AVA}\left(\mathrm{cm}^{2}\right)$ & $0.83 \pm 0.1$ & $0.83 \pm 0.1^{*}$ & $0.81 \pm 0.1$ \\
\hline Indexed AVA $\left(\mathrm{cm}^{2}\right)$ & $0.46 \pm 0.1$ & $0.47 \pm 0.1^{*}$ & $0.45 \pm 0.1$ \\
\hline $\begin{array}{l}\text { Aortic valve mean gradient } \\
\qquad(\mathrm{mm} \mathrm{Hg})\end{array}$ & $30.5 \pm 6.3$ & $30 \pm 6.5^{*}$ & $32.1 \pm 5.3$ \\
\hline $\begin{array}{l}\text { Aortic valve peak gradient } \\
\qquad(\mathrm{mm} \mathrm{Hg})\end{array}$ & $52.4 \pm 11.4$ & $51.4 \pm 11.4^{*}$ & $55.8 \pm 10.8$ \\
\hline Peak velocity (m/s) & $3.6 \pm 0.4$ & $3.5 \pm 0.4^{*}$ & $3.7 \pm 0.4$ \\
\hline LA area $\left(\mathrm{cm}^{2}\right)$ & $22.9 \pm 7$ & $23.2 \pm 7.6^{*}$ & $21.9 \pm 4.3$ \\
\hline $\begin{array}{l}\text { Pulmonary systolic arterial } \\
\text { pressure }(\mathrm{mm} \mathrm{Hg})\end{array}$ & $40.1 \pm 11.9$ & $40.6 \pm 11.9$ & $38.5 \pm 11.9$ \\
\hline
\end{tabular}

especially with the use of the continuity equation because errors in measuring the LVOT diameter, the assumption of a circular LVOT, and error in tracing the velocity time interval could occur. Doppler angle dependency could also explain the reduced valve gradient. These echocardiographic challenges and recognition of the term "paradoxical LF LG severe AS" (defined as an SVI of $\leq 35 \mathrm{~mL} / \mathrm{m}^{2}$ ) have led to an increased interest in the entity of LG severe AS. Patients with LF LG severe AS were reported to be older, more often female, and to have a greater incidence of hypertension. The heart was reported to have concentric LV remodeling, a greater degree of myocardial fibrosis, and a smaller cavity, which can preserve myocardial contractility with a reduced cardiac output. ${ }^{3,6,7,15,16}$ The 2012 European Society of Cardiology guidelines for managing valvular heart disease have recommended AVR (level IIa recommendation) for those patients but only after careful confirmation of severe AS. ${ }^{1}$ The authors of the guidelines would emphasize the diagnostic difficulty and also raise the option that some patients in that group might actually have moderate AS. The inconsistency between gradients and the AVA could also have been secondary to an AVA cutoff of $1 \mathrm{~cm}^{2}$ (in contrast to $0.8 \mathrm{~cm}^{2}$ ), which was also discussed in an editorial by Zoghbi ${ }^{17}$ and mentioned by Pibarot and Dumesnil. ${ }^{18}$ Thus, we studied the effect of AVR in a large cohort of patients with LG severe AS. The large cohort allowed us to explore the prognostic effect of 


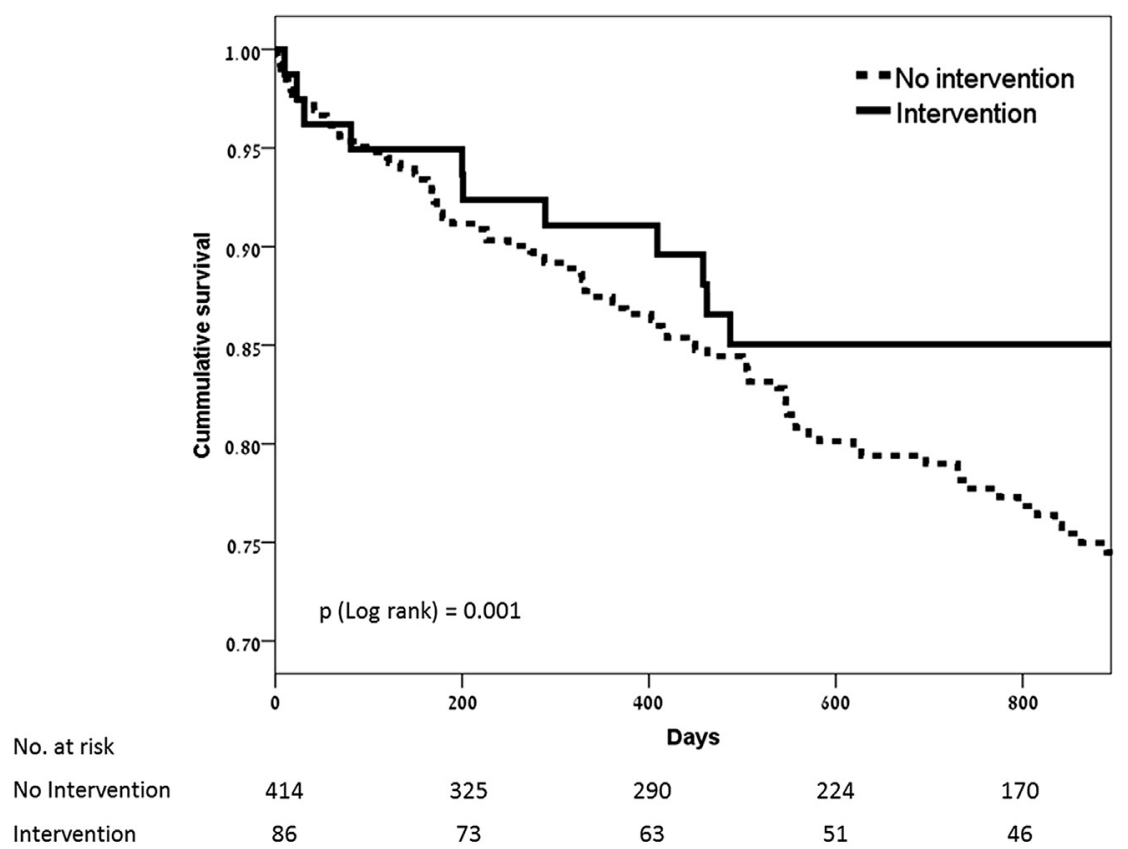

FIGURE 1. Mantle-Byar survival curve of the study population demonstrating that aortic valve intervention was associated with better survival $(P<.05)$.

aortic valve intervention on subgroups stratified by $\mathrm{LF}$ and $\mathrm{NF}$ or a reduced AVA $\left(\leq 0.8 \mathrm{~cm}^{2}\right)$.

\section{Prognosis of LG Severe AS}

Several studies have evaluated the prognosis of patients with LF, LG severe AS and a preserved EF and showed reduced overall survival. Although the perioperative mortality was increased, AVR was associated with improved survival. $3,6,7,10-13,19-21$ However, Jander and colleagues $^{9}$ reported outcomes similar to those of patients with moderate AS, with no difference between those with LF and NF. The prognosis was similar in the medically and surgically treated patients. In the present study, AVR was associated with a better prognosis, regardless of the presence of NF or LF, consistent with previous reports by Hachicha and colleagues ${ }^{3}$ and Ozkan and colleagues. ${ }^{22}$ Recent data regarding LG, NF severe AS are worth discussion. Eleid and colleagues ${ }^{20}$ have revealed that patients with NF and LG severe AS did not benefit from AVR. In contrast, Mehrotra and colleagues ${ }^{23}$ showed that those patients had a prognosis similar to those with

TABLE 3. Multivariate Cox regression analysis

\begin{tabular}{llcc}
\hline \multicolumn{1}{c}{ Parameter } & HR & $\mathbf{9 5} \%$ CI & $\boldsymbol{P}$ value \\
\hline Male gender & 1.1 & $0.7-1.5$ & .8 \\
Age $>80 \mathrm{y}$ & 4.7 & $3.1-7.2$ & $<.001$ \\
Aortic valve area $\leq 0.8 \mathrm{~cm}^{2}$ & 1.7 & $1.1-2.4$ & $<.05$ \\
Body mass index $\left(\mathrm{kg} / \mathrm{m}^{2}\right)$ & 1 & $1-1.1$ & .3 \\
Ischemic heart disease & 1.2 & $0.8-1.8$ & .3 \\
Aortic valve replacement & 0.51 & $0.3-0.9$ & $<.05$ \\
\hline
\end{tabular}

$H R$, Hazard ratio; $C I$, confidence interval. moderate AS. Studying asymptomatic patients with LG and NF severe AS, Lancellotti and colleageus ${ }^{21}$ has shown better survival for those patients, although the group of patients was small. In contrast, Mohty and colleagues, ${ }^{13}$ in a cardiac catheterization study of symptomatic patients, have shown reduced long-term survival and improved survival with AVR, although these were high-risk patients. These conflicting reports were mentioned in an editorial by Pibarot and Dumesnil. ${ }^{18}$ The heterogeneity of NF LG severe AS was discussed; some patients could actually have had moderate AS because of the inconsistency in aortic valve grading related to the guidelines criteria, already stated in our report. Another group of patients might have a small body size, such that the AVA might be $<1 \mathrm{~cm}^{2}$ but the index valve area would be $>0.6 \mathrm{~cm}^{2}$; thus, these patients should be treated as having moderate AS. The inconsistency in the prognosis seen among studies can be explained by the inconsistency in the definition of severe AS. Studies that defined severe AS by an indexed AVA of $<0.6 \mathrm{~cm}^{2}$ have succeeded in showing a prognostic effect of AVR. ${ }^{17,23}$ In the present study, all patients had an AVA of $<1 \mathrm{~cm}^{2}$ with an indexed AVA of $<0.6 \mathrm{~cm}^{2}$, supporting the positive effect on survival of AVR in patients with true NF, LG severe AS. Moreover, the positive effect of aortic valve intervention was noted in both patients with an AVA of $<0.8 \mathrm{~cm}^{2}$ and $>0.8 \mathrm{~cm}^{2}$. The importance of our findings are even more emphasized by the database characteristics: our database included data from an older population (age, $76 \pm 14$ years) with a high prevalence of other comorbidities $(59 \%$ hypertension, $32 \%$ diabetes mellitus, $40 \%$ coronary artery disease, $20 \%$ chronic renal 
No Intervention Aortic Valve Intervention
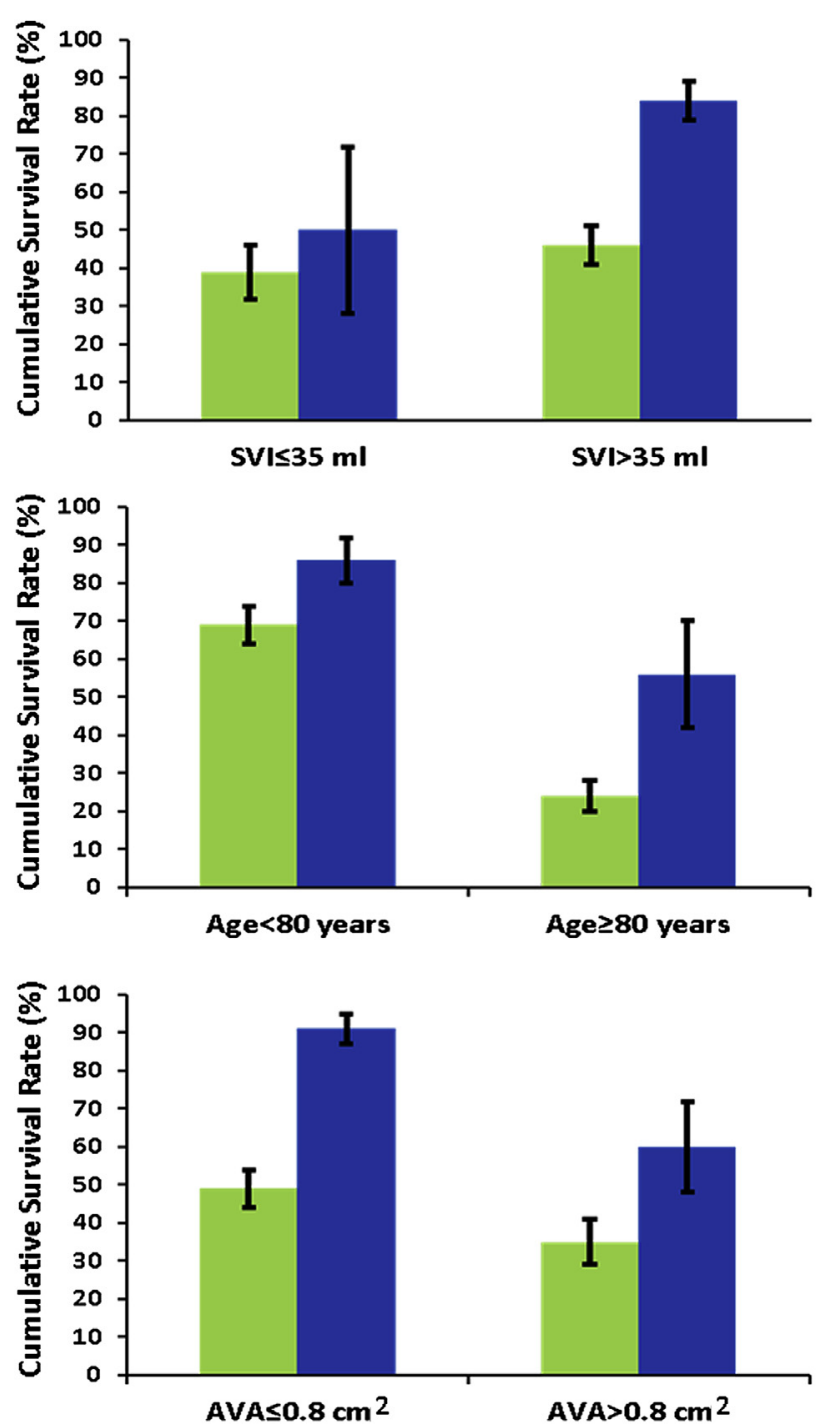

FIGURE 2. Effect of aortic valve intervention on the cumulative survival rate in the subgroups. A positive effect for aortic valve intervention was seen in all 3 subgroups: low flow versus normal flow (a stroke volume index $[S V I]$ of $<35 \mathrm{vs}>35 \mathrm{~mL} / \mathrm{m}^{2}$ ), older age ( $>80 \mathrm{vs}<80$ years), and an aortic valve area $(A V A)$ cutoff of $0.8 \mathrm{~cm}^{2}$ versus $1 \mathrm{~cm}^{2}$.

failure). The subgroup of older patients (age, $>80$ years), who were less likely to have undergone aortic valve intervention and had a worse prognosis, had improved survival with intervention, emphasizing the importance of intervention, especially in a high-risk population. In general, our analysis has supported intervention for patients with LG severe AS, regardless of the other clinical or echocardiographic parameters.

\section{Study Limitations}

This was a retrospective, single-center analysis, and decisions on medical or surgical intervention were at the discretion of the treating physician. We did not have access to those records. Data regarding symptoms, pharmacologic treatment, and functional class at the baseline echocardiographic examination and the surgical findings and perioperative complications were not available. Because our institution is a tertiary referral center, with a large-volume cardiothoracic surgical department, we believe our data might have been bias by a high frequency of symptomatic patients who were referred for aortic valve intervention, although we did not have a high percentage of aortic valve intervention. The entity of LF, LG severe AS was introduced during the study period; thus, the treatment strategy might have changed. We reported all-cause mortality only, because the cause of death was not available from the Israeli Ministry of Interior National Registry.

The blood pressure was not documented for all patients during the echocardiographic examination; therefore, valvuloarterial impedance was not included in our analysis. The LV contractile reserve and energy loss index were also not reported. The EF was visually estimated by the reader and was not evaluated using a quantitative method. Previous studies have shown a good correlation between the visually estimated EF and the calculated EF. The AVA was calculated using continuity equations, where errors might occur. Eleid and colleague ${ }^{20}$ have shown a good correlation between echocardiography and cardiac catheterization in calculating the AVA in patients with LG severe AS.

\section{CONCLUSIONS}

The present study has shown that aortic valve intervention will be associated with improved survival for patients with LG severe AS and a preserved EF. This positive effect was noted in patients with both LF and NF, emphasizing the importance of recognizing this entity and early referral for surgical AVR.

\section{References}

1. Vahanian A, Alfieri O, Andreotti F, Antunes MJ, Barón-Esquivias G, Baumgartner $\mathrm{H}$, et al. Guidelines on the management of valvular heart disease (version 2012): the Joint Task Force on the Management of Valvular Heart Disease of the European Society of Cardiology (ESC) and the European Association for Cardio-Thoracic Surgery (EACTS). Eur J Cardiothorac Surg. 2012;42:S1-44.

2. Bonow RO, Carabello BA, Chatterjee K, de Leon AC Jr, Faxon DP, Freed MD, et al. 2008 Focused update incorporated into the ACC/AHA 2006 guidelines for the management of patients with valvular heart disease: a report of the American College of Cardiology/American Heart Association Task Force on Practice Guidelines. J Am Coll Cardiol. 2008;52:e1-142.

3. Hachicha Z, Dumesnil JG, Bogaty P, Pibarot P. Paradoxical low flow, low gradient severe aortic stenosis despite preserved ejection fraction is associated with higher afterload and reduced survival. Circulation. 2007;115:2856-64

4. Minners J, Allgeier M, Gohlke-Bärwolf C, Kienzle RP, Neumann FJ, Jander N. Inconsistencies of echocardiographic criteria for the grading of aortic valve stenosis. Eur Heart J. 2008;29:1043-8.

5. Minners J, Allgeier M, Gohlke-Bärwolf C, Kienzle RP, Neumann FJ, Jander N. Inconsistent grading of aortic valve stenosis by current guidelines: hemodynamic studies in patients with apparently normal left ventricular function. Heart. 2010; 96:1463-8. 
6. Dumesnil JG, Pibarot P, Carabello B. Paradoxical low flow and/or low gradient severe aortic stenosis despite preserved left ventricular ejection fraction: implications for diagnosis and treatment. Eur Heart J. 2010;31:281-9.

7. Barasch E, Fan D, Chukwu EO, Han J, Passick M, Petillo F, et al. Severe isolated aortic stenosis with normal left ventricular systolic function and low transvalvular gradients: pathophysiologic and prognostic insights. J Heart Valve Dis. 2008;17:81-8.

8. Christensen KL, Ivarsen HR, Thuesen L, Kristensen BO, Egeblad H. Aortic valve stenosis: fatal natural history despite normal left ventricular function and low invasive peak-to-peak pressure gradients. Cardiology. 2004;102:147-51.

9. Jander N, Minners J, Holme I, Gerdts E, Boman K, Brudi P, et al. Outcome of patients with low-gradient "severe" aortic stenosis and preserved ejection fraction. Circulation. 2011;123:887-95.

10. Clavel MA, Dumesnil JG, Capoulade R, Mathieu P, Sénéchal M, Pibarot P. Outcome of patients with aortic stenosis, small valve area and low-flow, low-gradient despite preserved left ventricular ejection fraction. J Am Coll Cardiol. 2012;60:1259-67.

11. Belkin RB, Khalique O, Aronow WS, Ahn C, Sharma M. Outcomes and survival with aortic valve replacement compared with medical therapy in patients with low-, moderate-, and severe-gradient severe aortic stenosis and normal left ventricular ejection fraction. Echocardiography. 2011;28:378-87.

12. Pai RG, Varadarajan P, Razzouk A. Survival benefit of aortic valve replacement in patients with severe aortic stenosis with low ejection fraction and low gradient with normal ejection fraction. Ann Thorac Surg. 2008;86:1781-90.

13. Mohty D, Magne J, Deltreuil M, Aboyans V, Echahidi N, Cassat C, et al. Outcome and impact of surgery in paradoxical low-flow, low-gradient severe aortic stenosis and preserved left ventricular ejection fraction: a cardiac catheterization study. Circulation. 2013;128:S235-42.

14. Mantel N, Byar DP. Evaluation of response-time data involving transient states: an illustration using heart-transplant data. J Am Stat Assoc. 1974;69:81-6.
15. Weidemann F, Herrmann S, Störk S, Niemann M, Frantz S, Lange V, et al. Impact of myocardial fibrosis in patients with symptomatic severe aortic stenosis. Circulation. 2009;120:577-84.

16. Herrmann S, Störk S, Niemann M, Lange V, Strotmann JM, Frantz S, et al. Low-gradient aortic valve stenosis myocardial fibrosis and its influence on function and outcome. J Am Coll Cardiol. 2011;58:402-12.

17. Zoghbi WA. Low-gradient "severe" aortic stenosis with normal systolic function: time to refine the guidelines? Circulation. 2011;123:838-40.

18. Pibarot P, Dumesnil JG. Paradoxical low-flow, low-gradient aortic stenosis: new evidence, more questions. Circulation. 2013;128:1729-32.

19. O'Sullivan CJ, Stortecky S, Heg D, Pilgrim T, Hosek N, Buellesfeld L, et al. Clinical outcomes of patients with low-flow, low-gradient, severe aortic stenosis and either preserved or reduced ejection fraction undergoing transcatheter aortic valve implantation. Eur Heart J. 2013;34:3437-50.

20. Eleid MF, Sorajja P, Michelena HI, Malouf JF, Scott CG, Pellikka PA. Flow-gradient patterns in severe aortic stenosis with preserved ejection fraction: clinical characteristics and predictors of survival. Circulation. 2013; 128:1781-9.

21. Lancellotti P, Magne J, Donal E, Davin L, O'Connor K, Rosca M, et al. Clinical outcome in asymptomatic severe aortic stenosis: insights from the new proposed aortic stenosis grading classification. J Am Coll Cardiol. 2012; 59:235-43

22. Ozkan A, Hachamovitch R, Kapadia SR, Tuzcu EM, Marwick TH. Impact of aortic valve replacement on outcome of symptomatic patients with severe aortic stenosis with low gradient and preserved left ventricular ejection fraction. Circulation. 2013;128:622-31.

23. Mehrotra P, Jansen K, Flynn AW, Tan TC, Elmariah S, Picard MH, et al. Differential left ventricular remodelling and longitudinal function distinguishes low flow from normal-flow preserved ejection fraction low-gradient severe aortic stenosis. Eur Heart J. 2013;34:1906-14.

\title{
EDITORIAL COMMENTARY
}

\section{Low-gradient severe aortic stenosis also benefits from aortic valve replacement}

\author{
Carlos A. Mestres, MD, PhD, FETCS
}

See related article on pages $2823-8$.

Aortic stenosis (AS) is a surgical disease, and patients are best treated with valve replacement at any age and condition, as it has been well documented over time. ${ }^{1-3}$ The

From the Department of Cardiovascular and Thoracic Surgery, Heart and Vascular Institute, Cleveland Clinic Abu Dhabi, Abu Dhabi, United Arab Emirates.

Disclosures: Author has nothing to disclose with regard to commercial support.

Received for publication Sept 28, 2014; accepted for publication Sept 28, 2014; available ahead of print Oct 22, 2014.

Address for reprints: Carlos A. Mestres, MD, PhD, FETCS, Department of Cardiovascular and Thoracic Surgery, Heart and Vascular Institute, Cleveland Clinic Abu Dhabi, Sowwah Square, Al Maryah Island, PO Box 112412, Abu Dhabi, United Arab Emirates (E-mail: MestreC@ClevelandClinicAbuDhabi.ae).

J Thorac Cardiovasc Surg 2014;148:2828-9

$0022-5223 / \$ 36.00$

Copyright (c) 2014 by The American Association for Thoracic Surgery

http://dx.doi.org/10.1016/j.jtcvs.2014.09.100 results of the study of transcatheter versus surgical aortic valve replacement (SAVR) in high-risk patients corresponding to the Placement of Aortic Transcatheter Valves (PARTNER) trial published in 2011 suggested that in high-risk patients with severe AS, transcatheter and surgical procedures for AVR were associated with similar survival at 1 year, although there were important differences in periprocedural risks. ${ }^{4}$ This was despite a number of wellacknowledged limitations, such as the noninferiority design, frequent unexpected withdrawals, and lack of statistical power for robust conclusions in specific subgroups of patients. It is expected that technologic advancement will improve outcomes if current procedural and postprocedural limitations are overcome and some indications clearly defined..$^{5-7}$ At this time, SAVR and transcatheter valve implantation are treatment options covering almost all possible groups of patients requiring an aggressive treatment of AS; however, there are still some doubts on 